\title{
Community Engagement with Older Adults to Evaluate Interprofessional Education in Allied Healthcare Students
}

\author{
Scott Heinerichs \\ West Chester University of Pennsylvania, sheinerichs@wcupa.edu \\ Mary Beth Gilboy \\ West Chester University, mgilboy@wcupa.edu \\ Stacie Metz \\ West Chester University of Pennsylvania, smetz@wcupa.edu \\ Melissa A. Reed \\ West Chester University of Pennsylvania, mreed3@wcupa.edu \\ Barbara E. Harrison \\ West Chester University of Pennsylvania, bharrison@wcupa.edu \\ Follow this and additional works at: https://nsuworks.nova.edu/ijahsp \\ Part of the Community Health and Preventive Medicine Commons, Geriatric Nursing Commons, and \\ the Recreational Therapy Commons
}

This Manuscript has supplementary content. View the full record on NSUWorks here: https://nsuworks.nova.edu/ijahsp/vol15/iss1/2

\section{Recommended Citation}

Heinerichs S, Gilboy M, Metz S, Reed MA, Harrison BE. Community Engagement with Older Adults to Evaluate Interprofessional Education in Allied Healthcare Students. The Internet Journal of Allied Health Sciences and Practice. 2017 Jan 01;15(1), Article 2.

This Manuscript is brought to you for free and open access by the College of Health Care Sciences at NSUWorks. It has been accepted for inclusion in Internet Journal of Allied Health Sciences and Practice by an authorized editor of NSUWorks. For more information, please contact nsuworks@nova.edu. 


\title{
Community Engagement with Older Adults to Evaluate Interprofessional Education in Allied Healthcare Students
}

\begin{abstract}
Purpose: To examine students' perceptions of interprofessional education (IPE) as a result of their participation in a community engagement experience with older adults. Methods: Thirty-six students enrolled in the undergraduate majors of athletic training, exercise science, and nutrition participated in an 8-week fall prevention program in two community dwelling senior centers. A one-group pretestposttest evaluation design was used to assess the IPE experience of the students. Students completed the University of the West England Interprofessional Questionnaire pre and post intervention. Results: Both pretest and posttest student self-assessments of communication and teamwork skills ranged from slightly positive to neutral (means from 2.0 to 2.6). Students reported a statistical change in attitude from neutral $(M=2.3, S D+1.1)$ in the direction of slightly positive $(M=2.0, S D+1.1)$ toward being able to become quickly involved in new teams/groups from pretest to posttest $t(26)=2.53, p=.018 ; d=0.49 .95 \%$ of students strongly agreed or agreed that the experience enabled them to interact with an unfamiliar and unique population as well as increased their understanding of other allied healthcare disciplines as a result of participation. No individual items nor the summary score exhibited statistical improvements over time. Conclusion: Overall, the intervention was successful in describing the IPE positive experiences and attitudes of undergraduate allied healthcare students when working in a senior adult population.
\end{abstract}

\section{Author Bio(s)}

Scott Heinerichs, EdD, ATC is a Professor of Sports Medicine at West Chester University in West Chester, PA. He is also a licensed athletic trainer in the state of Pennsylvania.

Marybeth Gilboy, PhD, RN is an Associate Professor of Nutrition at West Chester University in West Chester, PA. She is also a licensed registered dietitian in the state of Pennsylvania.

Stacie Metz, PhD, MSW is a Professor of Graduate Social Work at West Chester University in West Chester, PA. She is also a licensed social worker in the state of Pennsylvania.

Melissa Reed, PhD, ACSM CCE-P is an Associate Professor of Exercise Science at West Chester University in West Chester, PA. She is also a certified exercise physiologist.

Barbara Harrison, PhD, APRN, FGSA, is an Associate Professor of Nursing at West Chester University in West Chester, PA. She is also a licensed nurse practitioner in the state of Pennsylvania.

PhD, APRN, FGSA 


\title{
TUAHSP \\ The Internet Joưnal of Allied Health Sciences and Practice
}

Dedicated to allied health professional practice and education

Vol. 16 No. 1 ISSN 1540-580X

\section{Community Engagement with Older Adults to Evaluate Interprofessional Education in Allied Healthcare Students}

\author{
Scott Heinerichs, EdD, ATC \\ Mary Beth Gilboy, PhD, RN \\ Stacie Metz, PhD, MSW \\ Melissa A. Reed, PhD, ACSM, CCE-P \\ Barbara E. Harrison, PhD, APRN, FGSA \\ West Chester University of Pennsylvania \\ United States
}

\begin{abstract}
Purpose: To examine students' perceptions of interprofessional education (IPE) as a result of their participation in a community engagement experience with older adults. Methods: Thirty-six students enrolled in the undergraduate majors of athletic training, exercise science, and nutrition participated in an 8-week fall prevention program in two community dwelling senior centers. A onegroup pretest-posttest evaluation design was used to assess the IPE experience of the students. Students completed the University of the West England Interprofessional Questionnaire pre and post intervention. Results: Both pretest and posttest student selfassessments of communication and teamwork skills ranged from slightly positive to neutral (means from 2.0 to 2.6). Students reported a statistical change in attitude from neutral $(M=2.3, S D+1.1)$ in the direction of slightly positive $(M=2.0, S D+1.1)$ toward being able to become quickly involved in new teams/groups from pretest to posttest $(t=2.53, p=.018, d=0.49)$. Ninetyfive percent (95\%) of students strongly agreed or agreed that the experience enabled them to interact with an unfamiliar and unique population as well as increased their understanding of other allied healthcare disciplines as a result of participation. No individual items nor the summary score exhibited statistical improvements over time. Conclusion: Overall, the intervention was successful in describing the IPE positive experiences and attitudes of undergraduate allied healthcare students when working in a senior adult population.
\end{abstract}

\section{INTRODUCTION}

Institutions of higher education play a key role in the transition from single discipline approaches in health professionals' education programs to a more integrative approach. Interprofessional education (IPE) has become a common term throughout institutions that offer medical and allied health programs. One of the catalysts for this movement was the 2010 release of a World Health Organization (WHO) report that indicated patient care outcomes could be improved if professionals who work together are familiar with each other's roles and scopes of practice. ${ }^{1}$ IPE occurs when students from two or more health-related professions learn "from, with and about each other to improve collaboration and improve health outcomes." 1 IPE can be learned and practiced during the formative stages of one's career; however, it is important to consider its implementation during the undergraduate experience. Researchers have reported that undergraduate students participating in IPE have an increase in the understanding of professional cultures, more positive attitudes towards collaboration, as well as fewer negative stereotypes of other professions..$^{2,3}$

Many of the studies on IPE only involve graduate health profession disciplines of medicine, nursing, dentistry, and pharmacy. ${ }^{4}$ However, allied health professionals make up about sixty percent of the total US health workforce. ${ }^{5}$ The WHO recommends that all health workers whose purpose is to enhance the health of people should be involved in IPE. ${ }^{1}$ The Association of Schools of Allied Health Professions was one of the eight professional associations to help create educational interventions and collect outcomes to address the following Healthy People 2020 Objective ECHP-19 "Increase the proportions of academic institutions with health professions education programs whose prevention curricula include interprofessional education experiences." ${ }^{\circ}$ Institutions 
of higher education with undergraduate allied health programs should consider engaging in IPE initiatives especially when the commonly seen health professions such as medicine, dentistry, nursing, and pharmacy are not part of the institution.

There have been a variety of methods used to evaluate IPE in allied healthcare programs at the undergraduate level. The majority of the research has focused on students working collaboratively in small or large groups using patient scenarios, simulation, or problem-based learning. ${ }^{7-15}$ One educational strategy that has yet to be evaluated in the literature is a community engagement experience with solely undergraduate students. Community engagement is considered a public service involving a partnership between an institution of higher education and the community. ${ }^{16}$ Institutions are able to provide the expertise of faculty members and student manpower to address the challenges facing a community. ${ }^{17}$ By having undergraduate students from different disciplines apply skills through a community engagement experience, students may better appreciate the importance of IPE for their future careers. Furthermore, a community experience provides the students with a different multidisciplinary student team that they would not have a chance to experience otherwise.

\section{Fall Prevention Program Overview}

To explore the inclusion of IPE in a community engagement experience, faculty members from athletic training, exercise science, and nutrition programs reached out collectively to create partnerships between the University and two separately owned and operated local senior centers. The faculty members recruited 4 graduate students and 36 undergraduate students from their respective disciplines through word of mouth to participate. The graduate students initially assisted the faculty in reviewing the literature to develop methods and exercises for the seniors to participate in for the program. Athletic training faculty were responsible for the creation of balance exercises. Exercise science faculty were responsible for strength training, and nutrition faculty were responsible for the nutritional education and awareness. After developing the program, the faculty members met with the multidisciplinary team of students a week prior to the start of the program for one hour to discuss the project including discipline specific responsibilities and an overview of IPE. This program was not part of the students' curriculum and was on a volunteer basis. The 8-week Fall Prevention Program combined each of the respective areas (balance, nutrition education, and strength training) and lasted for one hour, twice a week. The seniors who participated in this study were recruited through word of mouth. Faculty members visited the facilities prior to the beginning the eight week sessions to discuss the program as well as obtain informed consent. Any seniors who had any history of past or present endocrine disorders or cardiovascular disease were excluded from participation.

All faculty and students attended the weekly sessions at the center. The graduate student of each discipline (there were two exercise science graduate students) led the respective session, and faculty members were in attendance at all sessions to intervene if necessary. The undergraduate students assisted the graduate students in the execution of the program. Each day of the program consisted of a 30-minute nutrition education session followed by two fifteen-minute balance and strength sessions; the length of these sessions were chosen by the faculty. Prior to the start of each session, the graduate student met with all undergraduate students to answer questions and clear up misconceptions so everyone was aware of the content and responsibilities for that specific day. Within each session, undergraduate students worked in a multidisciplinary approach with the senior participants to assist with patient positioning and provide feedback during the balance and strength training sessions and during the nutrition sessions. The team taught the weekly objectives and nutrition messages to the senior participants. There was a 2:1 student to senior ratio for each part of the program. The purpose of this report is to describe the students' perceptions of IPE as a result of their participation in a community engagement experience with senior citizens.

\section{METHODS}

\section{Participants}

A sample of convenience was utilized for this study as thirty-six students (10 men, 26 women) from 3 allied healthcare programs (athletic training, exercise science, and nutrition) within the same public university participated in the project. Inclusion criteria were any students who were majoring in athletic training, exercise science, or nutrition during the fall 2014 semester. Students were not formally enrolled in an IPE course but were conveniently recruited through word of mouth by the faculty and encouraged to participate in the project. There were 4 graduate students, 17 senior, 12 junior, and 3 sophomore level students.

\section{Procedures}

A one-group pretest-posttest evaluation design was used to assess change in IPE from before to after the 8-week Fall Prevention Program. The study was approved by the West Chester University Institutional Review Board. Participants completed the University of the West England Interprofessional Questionnaire ${ }^{19}$ at the start and conclusion of the eight weeks. This questionnaire is comprised of four subscales (Communication and Teamwork Scale, Interprofessional Learning Scale, Interprofessional Interaction

(C) The Internet Journal of Allied Health Sciences and Practice, 2017 
Scale, and Interprofessional Relationship Scale). Given the nature of this project only three scales were given to the students: Communication and Teamwork Scale, Interprofessional Learning Scale, and Interprofessional Interaction Scale. This questionnaire has demonstrated good reliability and validity to measure providers' communication, teamwork skills, and attitudes towards professional collaboration. ${ }^{19}$

In the Communication and Teamwork Scale, students assessed their communication and group work skills on a 4-point Likert scale from 1 (Strongly agree) to 4 (Strongly disagree). An example of an item was "I am comfortable expressing my own opinions in a group, even when I know other people don't agree with them." Four item reversals were computed on pretest and posttest items, leading to a 1 to 4 response scale, with 1 indicative of a more positive self-assessment on communication and teamwork skills. The nine items displayed high pretest internal consistency $(\alpha=0.90)$ and were summed to create a summary score ranging from 9-36, with 9 indicating positive assessment.

The Interprofessional Learning Scale examined attitudes toward interprofessional learning. An example item included "Learning with students from other health and social care professions would be more beneficial to improving my teamwork skills than learning only with my peers." The items were measured on a 5-point Likert scale from 1 (Strongly agree) to 5 (Strongly disagree) with one item reversal, rendering a 1 to 5 scale, with 1 indicative of a more positive attitude. The nine items displayed high pretest internal consistency $(\alpha=0.98)$ and were summed creating a summary score ranging from $9-45$, with 9 indicating positive attitude towards interprofessional learning.

In the Interprofessional Interactions Scale, students assessed perceptions of interprofessional interaction from 1 (Strongly agree) to 5 (Strongly disagree). Six item reversals were computed, rendering a 1 to 5 response scale, with 1 indicative of a more positive perception of interprofessional interaction. An example item was "All members of health and social care professions have equal respect for each discipline." The nine items displayed good internal consistency at pretest $(\alpha=0.80)$ and were summed to create a summary score ranging from $9-45$, with 9 indicating positive perception of interprofessional interactions. Students at posttest were asked to provide feedback on their general perception and satisfaction with the experience. Three close-ended satisfaction items measured students' perception of the experience on a 5-point Likert scale from 1 (Strongly agree) to 5 (Strongly disagree) with 1 indicating positive attitudes towards IPE. Two open-ended items elicited feedback on the highlights of the experience and areas for improvement.

\section{Data Analysis}

IBM SPSS Statistics for Windows Version 22.0 was used for the descriptive and inferential analysis. Pretest-posttest descriptive statistics (mean and standard deviation) were presented for those students with complete data at both assessments ( $N=27$ ), nine individuals did not complete post-test assessments and were not included in the analysis. Statistical change over time in each item and summary score was measured using the paired-t test and non-parametric Wilcoxon matched-pairs signed-ranks test to account for small sample size (significance at 0.05). Conclusions did not differ between the parametric and non-parametric tests; hence, only the parametric test results were presented. Magnitude of effect was computed for statistically significant results using Cohen's $\mathrm{d}$ produced from $\mathrm{G}^{*}$ Power Version 3.1.9.2 (interpretation as $0.2=$ small, $0.5=$ medium, $0.8=$ large). ${ }^{21}$ Missing data were excluded from analysis. Lastly, at posttest, students $(n=25)$ were asked general perception/satisfaction questions in regards to IPE and summarized using relevant descriptive statistics. Evaluators generated themes from the two open-ended items' responses regarding highlights and areas for improvement. Themes were summed to identify the most frequently mentioned comments.

\section{RESULTS}

Pretest-posttest UWE Interprofessional Questionnaire findings are shown in Tables 1-3. Table 1 presents the pretest-posttest Communication and Teamwork Scale results of the 27 students completing the questionnaire at both assessment points. Overall, on average, both pretest and posttest student self-assessments of communication and teamwork skills ranged from slightly positive to neutral (means from 2.0 to 2.6), with only one item displaying statistical change over time. Students reported a change in attitude from neutral $(M=2.3, S D \pm 1.1)$ in the direction of slightly positive $(M=2.0, S D \pm 1.1)$ toward being able to become quickly involved in new teams/groups from pretest to posttest (Item \#8, $t=2.53, p=.018 ; d=0.49$ ).

(C) The Internet Journal of Allied Health Sciences and Practice, 2017 
Table 1. Pretest-Posttest UWE Interprofessional Questionnaire Communication and Teamwork Scale

\begin{tabular}{|c|c|c|c|c|c|c|}
\hline \multirow[b]{2}{*}{ Item ${ }^{\dagger}$} & \multicolumn{2}{|c|}{ Pretest } & \multicolumn{2}{|c|}{ Posttest } & \multicolumn{2}{|c|}{ Paired t-test } \\
\hline & $M$ & $S D$ & $M$ & SD & $t(d f)$ & $p$ \\
\hline $\begin{array}{l}\text { 1. Comfortable justifying recommendations/advice face to face with senior } \\
\text { people }\end{array}$ & 2.0 & 1.1 & 2.3 & 1.3 & $-1.14(26)$ & 0.265 \\
\hline 2. Comfortable explaining issue to people unfamiliar with topic & 2.4 & 1.0 & 2.2 & 1.2 & $1.41(26)$ & 0.170 \\
\hline $\begin{array}{l}\text { 3. Difficulty adapting my communication style to particular situations and } \\
\text { audiences (reversal) }\end{array}$ & 2.5 & 0.9 & 2.2 & 0.9 & $1.36(25)$ & 0.185 \\
\hline $\begin{array}{l}\text { 4. Prefer to stay quiet when other people in a group express opinions I } \\
\text { don't agree with (reversal) }\end{array}$ & 2.6 & 1.0 & 2.4 & 0.9 & $1.54(26)$ & 0.136 \\
\hline 5. Comfortable working in a group & 2.3 & 1.4 & 2.1 & 1.4 & $1.44(26)$ & 0.161 \\
\hline $\begin{array}{l}\text { 6. Uncomfortable putting forward my personal opinions in a group } \\
\text { (reversal) }\end{array}$ & 2.0 & 0.8 & 2.4 & 1.1 & $-1.43(26)$ & 0.164 \\
\hline 7. Uncomfortable taking the lead in a group (reversal) & 2.5 & 1.0 & 2.3 & 1.2 & $1.73(25)$ & 0.096 \\
\hline 8. Able to become quickly involved in new teams and groups & 2.3 & 1.1 & 2.0 & 1.1 & $2.53(26)$ & $0.018^{*}$ \\
\hline $\begin{array}{l}\text { 9. Comfortable expressing own opinions in a group, even when I know } \\
\text { other people don't agree }\end{array}$ & 2.4 & 0.8 & 2.3 & 1.0 & $0.65(26)$ & 0.523 \\
\hline $\begin{array}{l}\text { Communication and Team Work Scale Summary Score (ranging from } \\
\text { 9-36, with } 9 \text { representing a positive self-assessment of communication } \\
\text { and teamwork skills) }\end{array}$ & 21.4 & 6.8 & 20.3 & 8.6 & $1.66(24)$ & 0.110 \\
\hline
\end{tabular}

†Individual items measured from 1 (strongly agree) to 4 (strongly disagree); however, some items are reverse scored. Therefore, the items range from 1 (positive self-assessment of communication and teamwork skills) to 4 (negative self-assessment of communication and teamwork skills). ${ }^{*} \mathrm{p}<.05$

Table 2. Pretest-Posttest UWE Interprofessional Questionnaire Interprofessional Learning Scale

\begin{tabular}{|c|c|c|c|c|c|c|}
\hline \multirow[b]{2}{*}{ Item $^{\dagger}$} & \multicolumn{2}{|c|}{ Pretest } & \multicolumn{2}{|c|}{ Posttest } & \multicolumn{2}{|c|}{ Paired t-test } \\
\hline & $M$ & $S D$ & $M$ & $S D$ & $t(d f)$ & $p$ \\
\hline $\begin{array}{l}\text { 10. Skills communicating with patients/clients improved through } \\
\text { learning with students from other health and social care (HSC) } \\
\text { professions }\end{array}$ & 2.5 & 1.7 & 2.4 & 1.7 & $0.37(26)$ & 0.713 \\
\hline $\begin{array}{l}\text { 11. Skills in communicating with other HSC professionals improved } \\
\text { through learning with students from other HSC professions }\end{array}$ & 2.4 & 1.8 & 2.5 & 1.7 & $-1.00(26)$ & 0.327 \\
\hline $\begin{array}{l}\text { 12. Prefer to learn only with peers from my own profession } \\
\text { (reversal) }\end{array}$ & 2.7 & 1.4 & 2.4 & 1.4 & $1.99(26)$ & 0.058 \\
\hline $\begin{array}{l}\text { 13. Learning with students from other HSC professions likely to } \\
\text { facilitate subsequent working professional relationships }\end{array}$ & 2.6 & 1.7 & 2.5 & 1.6 & $0.81(26)$ & 0.425 \\
\hline $\begin{array}{l}\text { 14. Learning with students from other HSC professions more } \\
\text { beneficial to improving my teamwork skills than learning only } \\
\text { with my peers }\end{array}$ & 2.4 & 1.5 & 2.4 & 1.7 & $0.21(26)$ & 0.832 \\
\hline $\begin{array}{l}\text { 15. Collaborative learning would be positive learning experience for } \\
\text { all HSC students }\end{array}$ & 2.5 & 1.7 & 2.4 & 1.7 & $0.62(26)$ & 0.537 \\
\hline $\begin{array}{l}\text { 16. Learning with students from other HSC professions likely to } \\
\text { help to overcome stereotypes held about different professions }\end{array}$ & 2.3 & 1.6 & 2.4 & 1.7 & $-0.33(26)$ & 0.746 \\
\hline $\begin{array}{l}\text { 17. Would enjoy the opportunity to learn with students from other } \\
\text { HSC professions }\end{array}$ & 2.4 & 1.6 & 2.4 & 1.7 & $0.00(26)$ & 1.000 \\
\hline $\begin{array}{l}\text { 18. Learning with students from other HSC professions likely to } \\
\text { improve the service for patient/client }\end{array}$ & 2.4 & 1.7 & 2.4 & 1.7 & $0.44(26)$ & 0.663 \\
\hline $\begin{array}{l}\text { Interprofessional Learning Scale Summary Score (ranging from } \\
\text { 9-45, with } 9 \text { representing a positive self-assessment of } \\
\text { interprofessional learning) }\end{array}$ & 22.1 & 14.1 & 21.7 & 14.6 & $0.73(26)$ & 0.472 \\
\hline
\end{tabular}

†Individual items measured from 1 (strongly agree) to 5(strongly disagree); however, some items are reverse scored. Therefore, the items range from 1 to 5 , with 1 indicative of positive attitudes towards interprofessional learning. ${ }^{*} p<.05$ 
The findings from the Interprofessional Learning Scale are highlighted in Table 2. At pretest, students reported slightly positive to neutral attitudes towards interprofessional learning with individual item means ranging from 2.3 to 2.7 on a scale from 1 to 5 . No individual items nor the summary score exhibited statistical improvements over time.

Table 3 displays the results from the Interprofessional Interaction Scale. At pretest, students were responding with a neutral to slightly negative perception of interprofessional interactions with item means ranging from 2.8 to 3.6. Item \#27, Different health and social care professionals are not always cooperative with one another (reversal), demonstrated favorable statistical change from slightly negative $(M=3.6, S D \pm 0.8)$ to neutral $(M=3.0, S D \pm 0.9), t=2.86, p<.001 ; d=.57$.

Table 3. Pretest-Posttest UWE Interprofessional Questionnaire Interprofessional Interaction Scale

\begin{tabular}{|c|c|c|c|c|c|c|}
\hline \multirow[b]{2}{*}{ Item ${ }^{\dagger}$} & \multicolumn{2}{|c|}{ Pre } & \multicolumn{2}{|c|}{ Post } & \multicolumn{2}{|c|}{ Paired t-test } \\
\hline & $M$ & $S D$ & $M$ & $S D$ & $t(d f)$ & $p$ \\
\hline $\begin{array}{l}\text { 19. Different health and social care (HSC) professionals have } \\
\text { stereotyped views of each other (reversal) }\end{array}$ & 2.9 & 1.0 & 3.1 & 1.2 & $-1.49(25)$ & 0.148 \\
\hline $\begin{array}{l}\text { 20. Line of communication between all members of the HSC } \\
\text { professions is open }\end{array}$ & 3.1 & 0.9 & 3.0 & 0.8 & $0.83(25)$ & 0.416 \\
\hline $\begin{array}{l}\text { 21. There is status hierarchy in HSC that affects relationships } \\
\text { between professionals (reversal) }\end{array}$ & 2.8 & 1.1 & 3.1 & 1.0 & $-1.99(25)$ & 0.058 \\
\hline $\begin{array}{l}\text { 22. Different HSC professionals are biased in their views of each } \\
\text { other (reversal) }\end{array}$ & 3.0 & 1.1 & 3.0 & 1.1 & $-0.24(25)$ & 0.814 \\
\hline $\begin{array}{l}\text { 23. All members of HSC professions have equal respect for each } \\
\text { discipline }\end{array}$ & 3.1 & 1.0 & 3.2 & 0.9 & $-0.68(25)$ & 0.502 \\
\hline $\begin{array}{l}\text { 24. Easy to communicate openly with people from other HSC } \\
\text { disciplines }\end{array}$ & 3.0 & 0.8 & 2.7 & 1.0 & $1.44(25)$ & 0.161 \\
\hline $\begin{array}{l}\text { 25. Not all relationships between HSC professionals are equal } \\
\text { (reversal) }\end{array}$ & 3.0 & 0.9 & 2.8 & 1.0 & $1.00(25)$ & 0.327 \\
\hline $\begin{array}{l}\text { 26. HSC professionals do not always communicate openly with one } \\
\text { another (reversal) }\end{array}$ & 3.0 & 1.1 & 3.0 & 1.0 & $0.33(25)$ & 0.746 \\
\hline $\begin{array}{l}\text { 27. Different HSC professionals are not always cooperative with one } \\
\text { another (reversal) }\end{array}$ & 3.6 & 0.8 & 3.0 & 0.9 & $2.86(25)$ & $0.000^{*}$ \\
\hline $\begin{array}{l}\text { Interprofessional Interaction Scale Summary Score (ranging } \\
\text { from } 9-45 \text {, with } 9 \text { representing a positive self-assessment of } \\
\text { interprofessional interaction) }\end{array}$ & 27.6 & 5.5 & 27.1 & 6.0 & $0.80(25)$ & 0.431 \\
\hline
\end{tabular}

†Individual items measured from 1 (strongly agree) to 5(strongly disagree); however, some items are reverse scored. Therefore, the items range from 1 to 5 , with 1 indicative of positive attitudes towards interprofessional interactions. ${ }^{*} p<.05$

At posttest, 25 students also commented on their general satisfaction with the experience (response rate of $71 \%$ ). Three closeended satisfaction items measured students' perception of the experience. On average, $95 \%$ of students strongly agreed or agreed that the experience 1) enabled them to interact with a population of people they would not have had the opportunity to interact with as part of their curriculum, and 2) helped them to understand the roles of other allied healthcare disciplines as a result of participation. Ninety percent strongly agreed or agreed that as a result of their participation they have a better understanding of IPE.

Two open-ended questions elicited feedback on the experience's highlights and areas for improvement. Twenty-one of the 25 students provided highlights of the experience. The most frequently reported highlights of the experience consisted of interdisciplinary nature $(n=8)$, seeing improvement and enthusiasm in clients $(n=8)$, working with seniors $(n=7)$, and learning/applying skills in practice $(n=5)$.

The strength of the interdisciplinary nature of the experience was highlighted in student comments such as

"Being able to build relationships with other healthcare professionals and the seniors"

"This experience has given me a new insight and appreciation for students in the nutrition and exercise science program!

They did a great job!"

(C) The Internet Journal of Allied Health Sciences and Practice, 2017 
"Working with senior level individuals and others within the healthcare profession. Seeing their lesson made me value

their work."

Areas for improvement were elicited and 20 of the 25 students provided feedback. The most frequently reported areas of improvement included none $(n=4)$, more time needed $(n=4)$, attendance/organization $(n=4)$, location too far $(n=3)$, more communication with students from other disciplines $(n=2)$, and other comments $(n=3)$. Specifically, students suggested more communication with students from different disciplines during the program. Their comments included

"...it would be helpful if the different disciplines of the program communicated more about what they were doing and their progress [goals, struggles, progress] ..."

"Include a mid-program group meeting to share progress and discuss program"

\section{DISCUSSION}

The findings of this study compliment previous studies regarding how IPE can be implemented successfully using community engagement as a teaching and learning strategy.2,19 The majority of the students responded favorably that the project allowed them to better understand IPE and the work of other disciplines, and provided them the opportunity to engage with a patient population they may have not otherwise had the opportunity to. Additionally, there were significant findings in students' ability to learn how to become quickly involved in new groups as well as how to cooperate with other allied healthcare students. This study's findings provide insight into the design and delivery of community engagement experiences for other institutions of higher education to consider. Students identified collaboration with their peers from other disciplines as being a highlight of this experience. Specific comments included

"Loved working with the nutrition and exercise science students."

"The experience has given me new insight and appreciation for students in the nutrition and exercise science program,

they did a great job."

"Being able to build relationships with other healthcare professionals and the seniors." These responses lend support to the majority of students indicating they strongly agree/agree that this experience enabled them to understand the roles of other allied healthcare disciplines and have a better understanding of interprofessional education as a result of their participation. The opportunity of the undergraduate students to actively participate in this project was beneficial for them to appreciate the work of the other disciplines and become more involved in their own discipline prior to a required practicum course. When students are not immersed in authentic IPE activities, their ability to appreciate and participate can be compromised.2,20 Having the students engage with the seniors applying their knowledge and skills helped facilitate a statistically significant change from pre to post in students as it relates to their ability to learn how to quickly become involved in new teams as well as how to cooperate with other disciplines. Participating in community engagement IPE can be difficult because of an inability to find appropriate sites as well as professional boundaries that may be imposed by disciplinary scopes of practice, regulation, and accreditation. ${ }^{21,22}$ However, allied health faculty should seek out opportunities for undergraduate students that are consistently looking for service partners in the region. Considering there are a growing number of senior citizens in our country local senior centers are an ideal place for faculty to consider. ${ }^{24}$

Undergraduate students may not consider working with this population until they are given a specific rotation as part of a clinical experience or internship, so it is important to present this earlier on in their curriculums. Community based programs for older adults support the needs of this age group because the focus of care for older adults is to encourage aging in place.24 This community engagement project allowed faculty and students to contribute to the health of our community's older adult population. This helps to support Healthy People 2020 Objective ECHP-19 "Increase the proportions of academic institutions with health professions education programs whose prevention curricula include interprofessional education experiences."6

Many of the students had not previously worked with this target audience, and students reported this exposure as a significant highlight of the project. All of the students were actively engaged in preparing and presenting the programs. This allowed them to practice skills learned in the classroom in real life settings. For example, the multidisciplinary group of students learned about using theoretical frameworks in nutrition education. During the program, they used strategies to support Health Belief Model constructs,

(c) The Internet Journal of Allied Health Sciences and Practice, 2017 
such as decreasing perceived barriers, to increase knowledge of the audience. Students reported excitement at observing improvements in the older adults from the pre to post measures of balance and strength. Specific comments included

"Watching the seniors grow not only in my own area of the study, but the other disciplines as well."

"Working with the seniors and seeing how much they enjoyed and benefitted from the program."

These findings support the project goals which were to provide patient centered care, interprofessional learning, enhance communication skills amongst the students, and engage in teamwork and collaboration with allied health disciplines.

There were several limitations to our study which help explain why there were fewer significant changes in the student's postquestionnaire responses following exposure to an IPE community engagement experience. Specifically, the institution's curricula does not currently have a didactic course focused on IPE. The authors were aware of this limitation and did set up two meetings at the beginning and end of the experience. However, scheduling more regular meetings to allow students to reflect and debrief on their experience may have allowed for a more significant change in student's post-questionnaire responses as these exercises have been proven to be effective in the literature as it relates to IPE. ${ }^{19}$ Another limitation was that though all students were required to observe and participate (when appropriate) with the other disciplines, there was no direct follow-up of this during the 8 weeks. Formative assessments on a weekly basis may have allowed students to make more explicit connections. Finally, much of the IPE literature is focused on graduate students, while this study looked at undergraduate students which are a different student population. $4,9,10$ Students at the undergraduate level have a different maturity level and a wider array of responsibilities as a student as they are not only taking courses within their major but also the general education curriculum and participating in a wide array of co-curricular experiences. This may have impacted their ability to see the relevance of their experiential learning without intentional and consistent reflection. Also, a small sample size of students contributes to the inability to demonstrate significance of some items. Additionally, the students who volunteered for the program may not represent the general allied health student body, therefore, lacks generalizability.

\section{CONCLUSION}

Overall, students had positive responses to this IPE experience with some significant positive attitudes towards being able to quickly work in new groups and a favorable shift in attitudes regarding other health care disciplines cooperating with one another. Using community engagement as an experiential learning method successfully allowed the undergraduate allied health students to work with a new population (senior citizens) and provided an opportunity to practice skills in a real life setting. However, if not directly aligned with a course in the curriculum, faculty should ensure appropriate reflections and assessments are developed for students to make appropriate connections of their experiences. Allied health faculty members of a variety of disciplines should explore community engagement projects to initiate IPE early in the undergraduate education experience so that our future allied health professionals are prepared for a multidisciplinary professional environment.

\section{References}

1. Framework for Action on Interprofessional Education \& Collaborative Practice. World Health Organization. Geneva: 2010. Retrieved at: http://www.who.int/hrh/resources/framework_action/en/ Accessed November 14, 2016.

2. Freeth D, Hammick M, Reeves S, Koppel I, Barr H. Effective Interprofessional Education: Development, Delivery, and Evaluation. Oxford: Blackwell Publishing; 2005.

3. Hind M, Norman I, Cooper S, Gill E, Hilton R, Judd P, Jones S. Interprofessional perceptions of health care students. J Interprof Care. February 2003;17(1):21-34. [PMID: 12772467]

4. Davidson M, Smith RA, Dodd KJ, Smith JS, O'Loughlan M. Interprofessional pre-qualification clinical education: a systematic review. Aust Health Review. 2008 February;32(1):111-20. [PMID: 18241153]

5. Healthforce Center. University of San Fransisco. Retrieved at: http://www.futurehealth.ucsf.edu/Public/CenterResearch/Home. aspx?pid=88. Accessed November 14, 2016.

6. Healthy People 2020. US Health and Human Services. Washington, DC. Retrieved at http://www.healthypeople.gov/. Accessed November 14, 2016.

7. Wellmon R, Gilin B, Knauss L, Inman Linn M. Changes in students attitudes toward interprofessional learning and collaboration arising from a case-based educational experience. J Allied Health. 2012 Spring;41(1):26-34. [PMID: 22544405]

8. Cusack T, O'Donoghue G. The introduction of an interprofessional education module: students' perceptions. Qual Prim Care. 2012;20(3):231-8. [PMID: 22828679]

9. Cavanaugh JT, Konrad SC. Fostering the development of effective person-centered healthcare communication skills: an interprofessional shared learning model. Work. 2012;41(3):293-301. [PMID: 22398498]

() The Internet Journal of Allied Health Sciences and Practice, 2017 
10. Eccott L, Greig A, Hall W, Lee M, Newton C, Wood V. Evaluating students' perceptions of an interprofessional problem-based pilot learning project. J Allied Health. 2012 Winter;41(4):185-9. [PMID: 23224285]

11. Gaudet J, Shekter-Wolfson L, Seaberg R, et al. Implementing and evaluating interprofessional education for health sciences students: early experiences from a Canadian college. J Interprof Care. 2007 August;21(4):459-61. [PMID: 17654162]

12. Buckley S, Hensman M, Thomas S, Dudley R, Nevin G, Coleman J. Developing interprofessional simulation in the undergraduate setting: experience with five different professional groups. J Interprof Care. 2012 September;26(5):362-9. [PMID: 22594349]

13. Seefeldt TM, Mort JR, Brockevelt B, et al. A pilot study of interprofessional case discussions for health professions students using the virtual world Second Life. Currents in Pharmacy Teaching \& Learning. October 2012;4(4):224-31. DOI: 10.1016/j.cptl.2012.05.007

14. Titzer J, Swenty C, Hoehn W. An Interprofessional Simulation Promoting Collaboration and Problem Solving among Nursing and Allied Health Professional Students. Clin Simulation Nurs. October 2012;8(8):e325-33. [NLM UID: 101486408]

15. Wamsley M, Staves J, Kroon L, et al. The impact of an interprofessional standardized patient exercise on attitudes toward working in interprofessional teams. J Interprof Care. 2012 Jan;26(1):28-35. [PMID: 22233365]

16. Chesney CE, Samuel J, Fuller DS. Outreach and engagement at Tennessee State University. J of Higher Educ Outreach and Engagement. 2009;13(3):67-87.

17. Linking Scholarship and Communities: The Report of the Commission on Community-Engaged Scholarship in the Health Professions, 2005. Retrieved at: https://ccph.memberclicks.net/assets/Documents/FocusAreas/linkingscholarship.pdf Accessed November 14, 2016.

18. Oandasan I, Reeves S. Key elements for interprofessional education. Part 1: the learner, the educator and the learning context. J Interprof Care. 2005 May;19 Suppl 1:21-38. [PMID: 16096143]

19. Pollard KC, Miers MR, Gilchrist M. Collaborative learning for collaborative working? Initial findings from a longitudinal study of health and social care students. Health Soc Care Community. 2004 July;12(4):346-58. [PMID: 15272890]

20. Morison S, Jenkins J. Sustained effects of interprofessional shared learning on student attitudes to communication and team working depend on shared learning opportunities on clinical placement as well as in the classroom. Med Teach. 2007 June;29(5):464-70. [PMID: 17885972]

21. Myers CT, O'Brien SP. Teaching interprofessional collaboration: Using online education across institutions. Occup Ther Health Care. 2015 Sep;29(2):178-185. [PMID: 25821890]

22. Beth MRM, Lim PH, Pandi CR. Interprofessional learning in nursing - a review. International E-Journal of Science, Medicine \& Education. 2015;9(1):9-20.

23. Taylor EA, Cook D, Cunningham R, King S, Pimlott $T$. Changing attitudes- health sciences students working together. Internet $\mathrm{J}$ of Allied Health Sci Prac. 2004;2(3). Retrieved at: http://nsuworks.nova.edu/ijahsp/vol2/iss3/4/. Accessed November 14, 2016.

24. Ortman JM, Velkoff V, Hogan H. An aging nation: the older population in the United States. Current Population Reports. 2014. P25-1140. U.S. Census Bureau. Washington, DC. Retrieved at: http://www.census.gov/prod/2014pubs/p25-1140.pdf. Accessed November 14, 2016. 